\title{
Por que os resultados econômicos esperados para o final do governo Lula da Silva não nos asseguram uma estabilidade macroeconômica consistente?t
}

\author{
Fernando Ferrari Filho*
}

RESUMO - O breve artigo objetiva mostrar que, a despeito de alguns indicadores econômicos auspiciosos observados no último ano do governo Lula da Silva, tais como PIB, taxa de desemprego etc, a economia brasileira ainda encontra-se longe de uma trajetória de estabilidade macroeconômica, entendida como inflação sob controle, crescimento econômico robusto e equilíbrio externo.

Palavras-chave: Economia brasileira. Governo Lula da Silva. Política macroeconômica.

Ao aproximar-se o final dos governos Lula da Silva, 2003-2010, a análise de alguns indicadores econômicos do País parecem sugerir que a economia brasileira finalmente encontrou seu rumo para uma trajetória de crescimento estável e com inclusão social, visto que em 2010 o PIB deverá crescer 7,5\%, a taxa média de desemprego alcançará o menor valor desde o início da nova série da Pesquisa Mensal de Emprego do IBGE, iniciada em 2002, o rendimento médio dos trabalhadores deverá atingir os $\mathrm{R} \$ 1.450,00$, patamar mais elevado da série histórica do IBGE, os níveis de miséria absoluta e de pobreza deverão apresentar quedas acentuadas e a inflação manter-se-á no intervalo das metas. Se, todavia, centrarmos as atenções não nos prováveis resultados desses indicadores econômicos do último ano do governo Lula da Silva, mas, sim, os analisarmos - ampliando, inclusive, os indicadores econômicos que são passíveis de análise dessa natureza - ao longo do período 2003-2010, a leitura econômica pode ter outra perspectiva.

A Tabela 1 nos mostra o seguinte:

TABELA 1 - INDICADORES MACROECONÔMICOS SELECIONADOS - BRASIL: 2003 - 2010

\begin{tabular}{|c|c|c|c|c|c|c|c|c|c|}
\hline Indicadores Ano & 2003 & 2004 & 2005 & 2006 & 2007 & 2008 & 2009 & $2010^{1}$ & Média \\
\hline Taxa de Inflação (IPCA) (\%) & 9,3 & 7,6 & 5,7 & 3,1 & 4,5 & 5,9 & 4,3 & 5,3 & 5,7 \\
\hline Taxa de Crescimento do PIB (\%) & 1,1 & 5,7 & 3,2 & 3,7 & 6,1 & 5,1 & $-0,2$ & 7,6 & 4,0 \\
\hline Taxa de Desemprego ( $\%)$ & 12,3 & 11,5 & 9,8 & 10,0 & 9,3 & 7,9 & 8,1 & 7,1 & 9,5 \\
\hline $\begin{array}{l}\text { Rendimento Médio do } \\
\text { Trabalhador }(\mathrm{R} \$)\end{array}$ & 862,60 & 909,40 & 1102,50 & 1180,83 & 1218,79 & 1260,2 & 1357,70 & 1450,00 & $\mathrm{x}$ \\
\hline Saldo Comercial (US\$ bilhões) & 24,8 & 33,6 & 44,7 & 46,1 & 40,0 & 24,7 & 24,6 & 16,0 & $\mathrm{x}$ \\
\hline Conta Corrente (US\$ bilhões) & 4,2 & 11,7 & 13,9 & 13,5 & 1,5 & $-28,2$ & $-24,3$ & $-50,0$ & $\mathrm{x}$ \\
\hline
\end{tabular}

\footnotetext{
† Artigo escrito em 3 novembro de 2010.

* Professor titular da Universidade Federal do Rio Grande do Sul, pesquisador do CNPq e vice-presidente da Associação Keynesiana Brasileira. Endereço eletrônico: ferrari@ufrgs.br.
} 
TABELA 1 (CONTINUAÇÃO) - INDICADORES MACROECONÔMICOS SELECIONADOS - BRASIL: $2003-2010$

\begin{tabular}{l|r|r|r|r|r|r|r|r|r}
\hline \multicolumn{1}{c}{ Indicadores Ano } & $\mathbf{2 0 0 3}$ & $\mathbf{2 0 0 4}$ & $\mathbf{2 0 0 5}$ & $\mathbf{2 0 0 6}$ & $\mathbf{2 0 0 7}$ & $\mathbf{2 0 0 8}$ & $\mathbf{2 0 0 9}$ & $\mathbf{2 0 1 0}^{\mathbf{1}}$ & Média $^{\text {200 }}$ \\
\hline Taxa de Câmbio Nominal, Média & 2,89 & 2,65 & 2,34 & 2,14 & 1,77 & 2,34 & 1,74 & 1,75 & x \\
em Fim de Período (R\$/US\$) & & & & & & & & & \\
Reservas Cambiais (US\$ bilhões) & 49,3 & 52,9 & 53,8 & 85,8 & 180,3 & 193,8 & 238,5 & 280,0 & x \\
Resultado Fiscal Primário/PIB (\%) & 3,9 & 4,2 & 4,3 & 3,8 & 3,9 & 4,1 & 2,1 & 2,5 & x \\
Dívida Líquida/PIB (\%) & 53,5 & 48,2 & 48,0 & 45,9 & 43,9 & 38,8 & 43,0 & 41,0 & x \\
\hline
\end{tabular}

FONTE: BCB, IBGE e IPEADATA.

NOTAS: (1) Para 2010, as previsões de inflação, PIB, saldo comercial, conta corrente, reservas cambiais, resultado primário/PIB e dívida líquida/PIB são do BCB, ao passo que as estimativas de desemprego e rendimento médio, tendo como referência os primeiros 9 meses do ano, são do IBGE.

- A inflação média entre 2003 e 2010 foi da ordem de 5,7\% ao ano, ainda elevada para os padrões internacionais, considerando-se, inclusive, a média inflacionária dos países emergentes. Ademais, em 2003 a meta de inflação não foi atingida, bem como em 2004 ela somente foi alcançada - diga-se de passagem, 0,4\% abaixo do limite superior de 8,0\% - após o Banco Central do Brasil (BCB) ter alterado tanto o alvo da meta quando o intervalo de variação da banda;

- A taxa média de crescimento do PIB foi da ordem 4,0\% ao ano. Ademais, o PIB apresentou uma volatilidade acentuada, caracterizando-se por um processo à la stopand-go;

- A taxa média de desemprego, apesar da geração de 15 milhões de empregos entre 2003 e 2010, foi aproximadamente 9,5\% ao ano;

- A balança comercial apresentou trajetórias bastante distintas ao longo dos dois mandatos de Lula da Silva: entre 2003 e 2006, o saldo comercial cresceu cerca de $86,0 \%$, passando de US $\$ 24,8$ bilhões para USS $46,1 \%$, ao passo que no segundo Governo, o saldo comercial apresentou uma queda de 68,0\%, atingindo um valor de US\$15,0 bilhões;

- Comportamento semelhante teve o saldo de balanço de pagamentos em transações correntes: até 2007, o referido saldo foi positivo e entre 2008 e 2010 o saldo de balanço de pagamentos em transações correntes acumulou um déficit da ordem de US\$102,5 bilhões $^{1}$;

- Por fim, o setor público apresentou uma dinâmica relativamente estável e confortável: por um lado, a relação resultado fiscal primário/PIB manteve-se próxima a 1 É importante ressaltar que, em princípio, o déficit do balanço de pagamentos em transações correntes não é preocupante, pelo menos no curto prazo, pelo fato de que as reservas cambiais encontram-se ao redor de US $\$ 280,0$ bilhões, o que faz com que o Brasil seja credor líquido. 
4,0\% entre 2003 e 2008 e foi reduzida, em 2009 e 2010, para cerca de 2,5\% devido às políticas fiscais contracíclicas implementadas para que o País enfrentasse a crise financeira internacional. Por outro, a razão dívida líquida/PIB caiu ao redor de 21,0\%, passando de 53,5\%, em 2003, para 42,0\%, em 2010 .

Esses resultados deixam claro que é temário supor que o legado econômico de Lula da Silva é de "mar de almirante". Ademais, observando atentamente a atual situação externa da economia brasileira, é necessário ter ciência de que, passado os efeitos da crise financeira internacional, voltamos a enfrentar "velhos" problemas do período da prosperidade, dentre os quais a tendência à apreciação cambial, cujos efeitos são a deterioração da balança comercial e o processo de desindustrialização ${ }^{2}$, bem como o viés do $\mathrm{BCB}$ em querer subordinar a política fiscal ao regime monetário.

O que nos leva a questionarmos a performance econômica do governo Lula da Silva e, principalmente, sermos céticos em relação ao seu legado econômico, tendo como referência alguns indicadores de atividade econômica e de preços para 2010? Nosso questionamento e ceticismo estão alicerçados, em grande parte, ao fundamento teórico da política econômica adotada entre 2003 e 2010.

Vejamos.

Como se sabe, a política econômica do governo Lula da Silva foi marcada pela continuação, e em alguns aspectos radicalização, da política econômica do governo Fernando Henrique Cardoso (FHC), durante seu segundo mandato, 1999-2002. Essa política foi alicerçada no tripé câmbio flexível, Lei de Responsabilidade Fiscal e, por conseguinte, metas de superávits fiscais e regime de metas de inflação.

O referido tripé da política econômica, por sua vez, foi conduzido de maneira ligeiramente diferente nos dois mandatos de Lula da Silva, sem, contudo, perder seu foco, qual seja, a estabilidade do processo inflacionário assegurada, explicitamente, pela política monetária restritiva e, implicitamente, pela taxa de câmbio apreciada.

No período 2003-2006, em especial durante a gestão do Ministro da Fazenda Antonio Palocci, a política econômica foi muito mais conservadora. Segundo Lula da Silva e as Autoridades Econômicas (AE), a ortodoxia da política econômica fazia-se necessária face à "herança maldita" - inflação em elevação e fragilidade externa - do governo FHC (FERRARI FILHO e

2 Maiores detalhes sobre a tendência de valorização do real e o processo de "desindustrialização" da economia brasileira, fenômeno conhecido na literatura econômica como "doença holandesa", pode ser encontrado em Bresser-Pereira (2007, Capítulo 4). 


\section{CARDIM DE CARVALHO, 2004).}

Dessa maneira, na ocasião, as metas de superávit fiscal foram elevadas para 4,25\% do PIB e os superávits fiscais obtidos entre 2003 e 2006 foram alocados não para a realização de investimentos em infraestrutura e em programas fundamentais, mas, sim, para assegurar tanto o pagamento do serviço da dívida pública quanto a sua redução em relação ao PIB.

A política monetária, por sua vez, foi articulada de forma a delegar ao presidente do BCB, Henrique Meirelles, a sua operacionalização de maneira a fazer com que a taxa de inflação convergisse para as expectativas de inflação sinalizadas pelo mercado. Nesse sentido, as taxas de juros reais variaram, entre 2003 e 2006, de 8,1\% ao ano e 12,5\% ao ano, sendo que a taxa média de juros real foi da ordem de $11,2 \%$ ao ano.

A consequência da ortodoxia fiscal e monetária, aliada à adoção de algumas reformas liberalizantes, fez com que, por um lado, o País alcançasse credibilidade junto ao Fundo Monetário Internacional e aos investidores financeiros nacionais e internacionais. Por outro, a política econômica ortodoxa acabou tendo impacto sobre a dinâmica produtiva: entre 2003 e 2006, o crescimento médio do PIB foi baixo e as taxas de desemprego mantiveram-se elevadas.

No segundo mandato de Lula da Silva, a política fiscal passou a ser conduzida de forma um pouco mais flexível, seja pelo fato de que os Ministros da Fazenda e do Planejamento, Guido Mantega e Paulo Bernardo, respectivamente, reduziram a meta de superávit fiscal de 4,25\% para 3,75\% do PIB, seja porque foi criado o Programa de Aceleração do Crescimento (PAC). Mais tarde, com a crise financeira internacional, a política fiscal tornar-se-ia ainda mais flexível, uma vez que algumas alíquotas de impostos (imposto de renda de pessoa física, imposto sobre operações financeiras - IOF - de crédito ao consumidor e imposto sobre produtos industrializados - setores automotivos e eletrodomésticos da "linha branca", em especial) foram reduzidas e os investimentos públicos vinculados ao PAC foram ampliados. Ademais, em 2009 a meta de superávit fiscal acabou sendo reduzida de 3,75 para 2,5\% do PIB.

Em contrapartida, a política monetária continuou sendo articulada de forma excessivamente conservadora: a taxa média de juros real, entre 2007 e 2010, foi da ordem de 6,0\% ao ano. Ademais, a ação do BCB frente à crise financeira internacional e seus desdobramentos no lado real da economia corroborou o conservadorismo da política monetária: inicialmente, em setembro de 2008, portanto no momento em que a crise eclodiu, o BCB elevou a taxa de juros básica, Selic, em 0,75\% - passando de 13,0\% ao ano para 13,75\% ao ano - , quando a maioria dos bancos centrais baixou suas taxas de juros básicas; segundo, a despeito de algumas iniciativas pontuais para injetar liquidez na economia e reativar o mercado de crédito ${ }^{3}$ o $\mathrm{BCB}$ 
iniciou o processo de redução da Selic somente no início de 2009, bem como sua queda foi lenta e gradual, atingindo em dezembro de 2009 o valor de $8,75 \%$ ao ano; e, por fim, a partir do segundo trimestre de 2010 o BCB, receoso que a inflação fugisse do controle, passou a elevar a Selic - atualmente ela se encontra em 10,75\% ao ano.

A política cambial ao longo dos dois mandatos do governo Lula da Silva seguiu, com exceção da depreciação abrupta imediatamente após a eclosão da crise financeira internacional, uma trajetória de apreciação, conforme se verifica na Tabela 1. Essa apreciação cambial, que acaba tendo um efeito transmissor positivo sobre os preços, contribuindo, assim, para que a inflação convirja para sua meta, originou-se, principalmente, pela absorção de "poupança externa", via capital de portfólio, face o diferencial entre as taxas de juros doméstica e internacionais e pela política de acumulação de reservas cambiais implementada pelo BCB durante o período de prosperidade econômica mundial. Somente recentemente, diga-se de passagem, as AE, preocupadas com as perspectivas de continuidade do processo de apreciação cambial e, por conseguinte, de recrudescimento da deterioração do balanço de pagamentos em transações correntes, resolveram elevar o IOF sobre os fluxos de capitais estrangeiros direcionados para o mercado de capitais e os títulos da dívida pública, visando, com isso, reduzir o ingresso dos referidos capitais e reverter à tendência de apreciação cambial.

Em suma, em nosso ponto de vista, a despeito da ligeira flexibilização da política econômica do governo Lula da Silva entre 2007-2010, em especial da política fiscal, a política macroeconômica alicerçada no tripé câmbio flutuante, metas de superávits fiscais e metas de inflação não assegura condições para que a economia brasileira cresça de forma sustentável e com inclusão social, ao longo do tempo.

Diante desta conclusão e tendo em vista a preocupante deterioração do setor externo brasileiro, principalmente em 2010, o que fazer para que a economia brasileira tenha estabilidade macroeconômica consistente - isto é, crescimento econômico robusto, desenvolvimento social e equilíbrio externo?

Centrando as atenções somente no plano macroeconômico, a ação das AE deve ser direcionada para os seguintes pontos:

- Seguindo a tradição keynesiana (KEYNES, 1980), a política fiscal deve estar ancorada tanto na administração de gastos públicos - algo completamente diverso de déficit público - quanto na política de tributação. No que diz respeito à administração

compulsórios para pequenos e médios bancos e grandes bancos, respectivamente; e criação de uma linha de crédito internacional para financiar as exportações, a partir de recursos disponibilizados pelas reservas internacionais. 
dos gastos públicos, deve haver a constituição de dois orçamentos: o corrente e o de capital. Assim sendo, o orçamento corrente deve estar relacionado ao fundo de recursos necessários à manutenção dos serviços básicos fornecidos pelo Estado à população sob sua guarda, tais como saúde pública, educação, segurança pública etc. Por sua vez, o orçamento de capital deve estar associado às despesas públicas referentes a investimentos produtivos levados a cabo pelo Estado para a manutenção da estabilidade no sistema econômico ${ }^{4}$. Em relação à política de tributação ela deve ter propósitos claros: por um lado, deve permitir que a renda desigualmente distribuída da sociedade seja realocada, tanto por tributação da renda, via sobretaxas, quanto por impostos sobre a herança; e, por outro, deve viabilizar, pela ampliação da capacidade de gasto do Estado, a expansão da demanda agregada do sistema econômico.

- A política monetária deve deixar claro aos agentes econômicos que os objetivos do BCB são tanto o controle da inflação quanto a redução do gap do produto, tal que eles (agentes econômicos) possam tomar suas decisões induzidas por ela (política monetária). Assim sendo, a flexibilização da política monetária é fundamental para dinamizar os níveis de consumo e investimento e para afetar a preferência pela liquidez dos agentes econômicos. Ademais, o BCB deve ter ciência de que a taxa de juros básica, Selic, somente é um instrumento eficaz para controlar a inflação quando ela é essencialmente de demanda, não sendo adequada para controlar a inflação causada por choques de oferta.

- As $\mathrm{AE}$ devem adotar uma política cambial que assegure a manutenção de uma taxa de câmbio competitiva e não gere pressões inflacionárias. Nesse sentido, a adoção de uma taxa de câmbio em conformidade com o mecanismo operacional de um regime de câmbio flutuante administrado (managed floating), visando não somente que as ações especulativas possam ser coibidas, mas que a taxa real efetiva de câmbio mantenha-se relativamente estável ao longo do tempo, é imprescindível para dinamizar a atividade exportadora e evitar efeitos pass-through do câmbio para os preços. Para assegurar a manutenção da taxa real efetiva de câmbio (TREC) de equilíbrio em um patamar competitivo a médio e longo prazo, propõe-se a criação de um Fundo de Estabilização Cambial, constituído por divisas compradas pelo governo com recursos fornecidos pelo Tesouro Nacional na forma de títulos da dívida pública,

4 Segundo Keynes (1980), o orçamento de capital pode ser deficitário, desde que os superávits necessariamente obtidos no orçamento corrente o financiem. 
que seria utilizado para a operacionalização da política de esterilização relacionada às compras de divisas. Este Fundo atuaria como um market maker no mercado de câmbio, (i) comprando moeda estrangeira toda a vez que a taxa de câmbio se apreciar de maneira persistente com respeito ao valor estimado da TREC de equilíbrio e (ii) vendendo moeda estrangeira toda vez que a taxa de câmbio se depreciar de forma persistente com respeito ao valor de equilíbrio da TREC. Para reduzir o esforço fiscal requerido para a implantação do Fundo de Estabilização Cambial, seria necessária a introdução de controles abrangentes de capitais no Brasil para reduzir os fluxos de entrada de divisas cambiais para a economia brasileira e diminuir, consequentemente, o esforço do governo de intervenção no mercado cambial ${ }^{5}$.

Concluindo, políticas keynesianas contracíclicas, fiscais e monetárias, e intervenções no mercado de câmbio são fundamentais para que o País tenha uma trajetória de crescimento econômico sustentável, com inclusão social, e equilíbrio intertemporal de balanço de pagamentos de maneira que a economia brasileira não seja refém da armadilha do câmbio e, por conseguinte, dependa de "poupança externa".

\section{REFERÊNCIAS}

BANCO CENTRAL DO BRASIL. Disponível em:<http://www.bcb.gov.br>. Acesso em $11 / 2010$.

BRESSER-PEREIRA, L.C. Macroeconomia da estagnação: crítica da ortodoxia convencional no Brasil pós-1994. São Paulo: Editora 34, 2007.

FERRARI FILHO, F.: CARDIM DE CARVALHO, F. J. El presidente Lula da Silva en el primer tercio de su mandato. Investigación Económica, LXIII (249): 55-74, julio-septiembre, 2004.

FERRARI FILHO, F; PAULA, L.F. Regime cambial, conversibilidade da conta capital e performance econômica: a experiência recente de Brasil, Rússia, Índia e China. In: FERRARI FILHO, FERRARI FILHO, F; SICSÚ, J. (Orgs.) Câmbio e controle de capitais: avaliando a eficiência de modelos macroeconômicos. Rio de Janeiro: Campus-Elsevier, 184-22, 2006.

INSTITUTO BRASILEIRO DE GEOGRAFIA E ESTATÍSTICA. Disponível em: <http:// www.ibge.gov.br>. Acesso em 11/2010.

5 Em relação aos mecanismos de controle de capitais, Ferrari Filho e Paula (2006: 190) apontam que os eles podem ocorrer de três formas: (i) controles diretos ou administrados, ou seja, restrição quantitativa de fluxos de capitais conforme suas origens, maturidade e destinações; (ii) controles indiretos ou baseados em preços, que são estabelecidos pela cobrança de impostos sobre fluxos de capitais entre países e/ou pela imposição de depósitos compulsórios incidentes sobre os fluxos de capitais ingressantes; e (iii) regulações financeiras, isto é, imposição de limites sobre posições cambiais de residentes. 
INSTITUTO DE PESQUISA ECONÔMICA APLICADA. Disponível em: < http://www. ipeadata.gov.br>. Acesso em 11/2010.

KEYNES, J. M. Activities 1940 - 1946: Shaping the post-war world employment (The Collected Writings of John Maynard Keynes, volume XXVII). London: Macmillan, 1980. 